\title{
Perception of Safety of Cyclists in Dublin City
}

\author{
Anneka R. Lawson ${ }^{1}$, Vikram Pakrashi ${ }^{2}$, Bidisha Ghosh ${ }^{1}$, W.Y. Szeto ${ }^{3}$ \\ ${ }^{1}$ Department of Civil, Structural and Environmental Engineering \\ Trinity College Dublin \\ ${ }^{2}$ Department of Civil and Environmental Engineering \\ University College Cork \\ ${ }^{3}$ Department of Civil Engineering \\ The University of Hong Kong
}

\begin{abstract}
In recent years, cycling has been recognized and is being promoted as a sustainable mode of travel. The perception of cycling as an unsafe mode of travel is a significant obstacle in increasing the mode share of bicycles in a city. Hence, it is important to identify and analyze the factors which influence the safety experiences of the cyclists in an urban signalized multi-modal transportation network. Previous researches in the area of perceived safety of cyclists primarily considered the influence of network infrastructure and operation specific variables and are often limited to specific locations within the network. This study explores the factors that are expected to be important in influencing the perception of safety among cyclists but were never studied in the past. These factors include the safety behavior of existing cyclists, the users of other travel modes and their attitude towards cyclists, facilities and network infrastructures applicable to cycling as well as to other modes in all parts of an urban transportation network. A survey of existing cyclists in Dublin City was conducted to gain an insight into the different aspects related to the safety experience of cyclists. Ordered Logistic Regression (OLR) and Principal Component Analysis (PCA) were used in the analysis of survey responses. This study has revealed that respondents perceive cycling as less safe than driving in Dublin City. The new findings have shown that the compliance of cyclists with the rules of the road increase their safety experience, while the reckless and careless attitudes of drivers are exceptionally detrimental to their perceived safety. The policy implications of the results of analysis are discussed with the intention of building on the reputation of cycling as a viable mode of transportation among all network users.
\end{abstract}

Keywords: Perceived safety, Multi-modal transportation network, Urban cycling, Questionnaire survey 


\section{Introduction}

There has been an increasing dependency of society on motorized vehicles in Dublin City over the past number of decades. This has raised significant concerns regarding growing traffic congestion, harmful vehicle emissions and associated public health problems. In 2005, the cost of congestion alone to the Greater Dublin Area was €2.5 billion (Dublin Chamber of Commerce, 2005). This is a huge threat to the competitiveness of Dublin as a city trying to attract investments. To combat these problems, non-motorized modes of transportation, like walking and cycling, are gaining attention from policy makers in recent years. Increased mode share of these sustainable modes of travel are expected to reduce vehicle numbers on the roads within the city, thereby reducing traffic congestion, vehicle emissions, and health problems associated with these vehicle emissions. In 2009, the Department of Transport published Ireland's first National Cycle Policy Framework (NCPF) (Department of Transport, 2009), which aims at increasing the bicycle commuter mode share to $10 \%$ by 2020 . At the time of publication of the NCPF, the mode share in Ireland stood at $1.9 \%$. The cycling mode share in Dublin City stood at 3.2\% in 2006 (Central Statistics Office, 2006; McMorrow and Ghosh, 2011). This is higher than the average rate in Ireland, but remains far below the 2020 target set out in the NCPF. In comparison with other cycling friendly countries and cities in Europe, the mode share is extremely low. Cycling mode shares in countries like the Netherlands, Denmark and Germany are on an average between $10 \%$ and $26 \%$ with some cities reaching 35\%-40\% (Ministerie van Verkeer en Waterstaat, 2009).

A significant obstacle to achieving this targeted mode share in Dublin City is the fact that cycling is perceived as an unsafe mode of travel. Studies have shown the risks of accident or injury due to cycling are much higher than while driving (Aultman-Hall and Kaltenecker, 1999; Zegeer, 1994). A study of the attitudes of cyclists and drivers in Dublin found that $21 \%$ of drivers do not cycle because they feel it is "too dangerous because of traffic" (Keegan and Galbraith, 2005). A report from the Irish Road Safety Authority (RSA) (Road Safety Authority, 2010) states that between 1998 and 2008 there were 144 cyclists (43 in County Dublin) fatally injured and 335 (115 in County Dublin) seriously injured on Irish roads. Despite the percentage of fatalities among cyclists contributing only $3.5 \%$ of all road fatalities between these years in Ireland, cycling remains a low preference mode of travel. This may be due to a large number of minor accidents unreported to authorities. The RSA report does not distinctly address minor injuries due to cycling accidents, although the RSA does recognize that cyclists are the most vulnerable road users (Road Safety Authority, 2010). Due to limited information, it is not possible to gauge the actual number of minor cycling accidents in Dublin. Many studies have estimated the extent to which underreporting of cycling accidents and underreporting of the severity of reported accidents occur across Europe (Waldman, 1977), Canada (Doherty et al., 2000) and the USA (Stutts and Hunter, 1998).

Previous research on cycling safety has mainly focused on the placement of cyclists within a multi-modal network and on the use of safety accessories such as helmets and light/reflectors. There are mixed opinions on the integration (Aultman-Hall and Hall, 1998b; Aultman-Hall and Kaltenecker, 1999; Forester, 1993; Moritz, 1997) or separation (Bíl et al., 2010; Hopkinson and Wardman, 1996; Parkin et al., 2007; Pucher, 2001; Tilahun et al., 2007; Wardman et al., 2007; Wegman et al., 2012) of cyclists from other road users. Separation within the road has been suggested as less safe for cyclists as drivers pay less 
attention and leave less space when overtaking (de Lapparent, 2005; Parkin and Meyers, 2010). There are studies which suggest that a well-connected network of various types of facilities is required to ensure cyclist safety (Dill, 2009; Pucher et al., 2010). There also exists much debate in relation to the use of safety accessories (Cameron et al., 1994; Depreitere et al., 2004; Ekman et al., 1997; McIntosh et al., 1998; Povey et al., 1999; Robinson, 2001; Scuffham et al., 2000; Scuffham and Langley, 1997; Welander et al., 1999). Recommending or making their use mandatory has been shown to be unsuccessful in encouraging their use among all cyclists (Ferguson and Blampied, 1991; Hagel et al., 2007; Osberg et al., 1998) and although their use decreases the risk of head injuries, enforcing mandatory use has had a detrimental effect on mode share which does not outweigh the health benefits of cycling.

Less research attention has been focused on investigating the perceptions of safety among cyclists. The majority of existing research conducted in this field is presented in Table 1, including variables collected as part of each study (not all variables were considered in the analysis of each study; not all analyzed variables were found significant). These studies have mainly been conducted in order to aid engineers and planners in the design, improvement and prioritization of road and intersection works to cater for cyclists. The majority of these studies asked cyclists to rate their overall risk perception of a route described by video-clips, simulations, survey or by completion of a test course. Each study examined a number of network geometry and operation specific variables in relation to the safety perceptions of cyclists which are listed as network specific variables in Table 1. Only two of the studies (Møller and Hels, 2008; Noland and Kunreuther, 1995) considered cyclist characteristics which are listed as cyclist specific variables in the table. Among the network specific variables, outside lane width, motorist speed and volume were considered by almost all studies mentioned in Table 1. The other popular operational variables considered in the literature include pavement surface quality, the trip generation potential of the surrounding area, the number of traffic lanes, the number of side roads, facility characteristics, turning vehicles and traffic mix at specific locations identified by the researchers. Parkin et al. (2007) uniquely considered the majority of the remaining operational variables as indicated in Table 1. Each of these analyses have tended to consider only a small number of variables and are usually specific to certain locations within the network, such as link segments, vehicle or bicycle crossings and roundabouts. The restricted nature of these previous researches establishes scope for the development of an exhaustive study on cyclist safety perceptions, containing all variables considered in previous research along with new variables which are expected to have an impact on cyclist safety perception and were not studied in the past.

This paper aims to investigate the overall perceptions of cyclists in a multi-modal, signalized transportation network, rather than targeting specific locations within the network. The network agents explored include existing cyclists and road users of other transportation modes, facilities and network infrastructures applicable to cycling as well as to other modes. The new variables investigated in this study include safety accessory use, bus, taxi and car driver's behavior, cyclist experience and confidence, trip purpose, weather conditions and the presence of accident 'black spots', etc. In particular, through Ordered Logistic Regression (OLR) and Principal Component Analysis (PCA) based models, all the aforementioned variables are found to be significant and have an impact on cyclist safety perception. More importantly, both the compliance of cyclists with the rules of the road and uncooperative driver attitudes are found to have direct implications on cycling policy. 
In this study, a questionnaire based survey on the different aspects of the safety of cyclists in an urban transportation network has been conducted on a large number of existing cyclists in Dublin City, Ireland. The survey responses have been analyzed to explore the aspects of safety of the cyclists in three main categories; the current safety behavior of the cyclists, the perception of safety of the cyclists, and the interaction of the cyclists with the elements of the network within a multi-modal transportation system. Three models, namely the safety behavior model, the perceived safety model, and the cyclist-network interaction model, have been developed via PCA or OLR to explore the three aspects. The perceptions studied are based on the self-reported personal experiences of cyclists in the transportation network of Dublin city. This investigation is complex, yet interesting, since the transportation infrastructures along with the conditions for cycling vary widely throughout the city.

The next two sections of this paper depict the data and the methods respectively, followed by the analysis section employing the three aforementioned models. The discussion on the policy implications and the limitations of this study are provided next. Finally, a conclusion is given.

\section{Data}

This section presents the transportation network characteristics of the study region, Dublin city, Ireland. This is followed by a sub-section pertaining to the collection of data. The profile of the respondent cyclists and a description of the survey data collected are presented next in two subsections, respectively.

\subsection{Study Region}

Dublin City is the capital of Ireland and the largest city in terms of area, residing and working population of the country (Central Statistics Office, 2006). The transportation network in Dublin City is primarily designed for the use of private vehicles. Other main modes of motorized transportation in Dublin City are Dublin Bus, Luas (tram), Dublin Area Rapid Transport (light rail) and Commuter trains (suburban railway networks). In 2006, nearly $16.4 \%$ of the commuter trips were made using non-motorized modes of transportation (McMorrow and Ghosh, 2011). However, the percentage of employees walking to their workplaces was much higher than that using bicycle as their preferred mode of commuter travel. The transportation network in Dublin City contains cycling facilities mainly in the form of cycle lanes; approximately $120 \mathrm{~km}$ of on-road cycle tracks, $50 \mathrm{~km}$ of shared bus-cycle lanes and $25 \mathrm{~km}$ of off-road cycle tracks exist in the network.

Despite the presence of these facilities, many threats exist to the cyclists in Dublin. A few of these threats are unforeseen ending of cycle lanes which expose cyclists to suddenly share their commuting space with other modes with high speed-difference; cars and taxis frequently making unexpected stops and turns, forcing cyclists to join oncoming traffic from behind. Also, poorly maintained cycling surfaces often result in falls causing injury and damage to property. Abrupt barriers in the form of signposts, on-street parking and the presence of bus-stops tend to encroach on the cycle lanes; entries to the cycle lanes are often not ramped and are unsafely kerbed. Also, new designs like speed breakers on cycle lanes near bus-stops have been reported to be uncomfortable, unsafe and unnecessary by many cyclists. These conditions and/or threats naturally lead to actual and perceived discomfort and a lack of safety for the cyclists. There are many more such factors or 
conditions which influence a cyclist's perception of safety in Dublin City. To understand which aspects of the transportation network prove most hostile to cyclists, a detailed analysis is required to track the factors that most strongly affect the actual and perceived safety of the cyclists in this network.

\subsection{Data Collection}

A fixed-response questionnaire based survey was conducted in order to gather information, previously unavailable in Dublin, on the perceived safety and safety behaviors of cyclists, with regards to the available cycling infrastructures, the use of safety accessories, the effect of prevalent road and weather conditions, as well as various other aspects of traveling by bicycle in Dublin's multi-modal network. The survey, conducted over a 3 month period between $7^{\text {th }}$ March and $1^{\text {st }}$ June, 2011, receiving 1,954 responses, collected information from existing cyclists, who regularly cycled in Dublin within the previous 12 months. The questionnaire was distributed among major Irish and multi-national companies, major universities in Dublin, governmental departments and through word of mouth. The questionnaire was also available on-line; the link to which was circulated via e-mail, posts on cycle club and group websites, cycling forums, and posts on social networking web-sites. Hardcopies of the questionnaire were available from local cycle repair shops and from the authors, upon request.

The survey questionnaire was divided into 3 sections, each corresponding to the focus of the separate models used in the analysis, collecting information on socio-demographics, trip purposes, trip distance, trip time, cycling infrastructure preferences, safety equipment preferences, information on the effects of adverse road and weather conditions as well as information on effects of interaction with other travel modes. At the beginning of each section of the survey, a short explanation of the focus of the section was given so that respondents were aware of why the questions were being asked. In particular, models related to safety behavior and cyclist-network interaction involved questions based on extensive literature review and discussions with cycling experts from the city council, National Transport Authority and cycling forums. These bodies were considered influential to the focus of the section. For the perception of safety model, the perceived safety was measured by asking specific questions on how safe the cyclist feels compared to driving in Dublin on a Likert scale (Jambu, 1991).

\subsection{Profile of Cyclists}

1,732 out of 1,954 responses were eligible for use in the analysis. The profile of the cyclists of Dublin who gave eligible responses to the survey has been presented in Table 2. The profile has been summarized according to the self-reported experience of the cyclists ('Inexperienced', 'Competent', or 'Highly Skilled'), socio-demographic characteristics (e.g., 'Age') and cyclists' trip characteristics (e.g., 'Regularity of Cycling') with a count and the corresponding percentage given for each combination of self-reported experience and characteristic (e.g., 'Male'). The percentage is calculated by dividing the count by the total number of eligible responses, 1732 , and multiplying the resulting quotient by $100 \%$. Hence, the sum of all the percentages under the same characteristic (e.g., age) equals $100 \%$.

The majority of the respondents were male (63.7\%) and were aged less than 45 years. According to the available statistics, the majority of the cycling population in Dublin City is male and less than 40 years of age (Central Statistics Office, 2006). Consequently, the 
respondent demographic of the survey is an unbiased representation of the cycling population of the city. The majority of respondents were either students (46.1\%) or in fulltime employment (44.4\%). Respondents were mainly single, living in shared accommodation (35.8\%), couples with resident child(ren) (24.1\%) or couples with no resident child(ren) (17.0\%). All respondents live within the Dublin area, as this is the study area of interest and $51.8 \%$ of respondents have a car that can be used on a day-to-day basis. Although the survey collected anonymous responses, no information on household income was collected as it was felt such a question may hinder the survey response rate.

\subsection{Data Description}

On average, the respondents cycle $9.54 \mathrm{~km}$ on a weekday and $6.85 \mathrm{~km}$ on a weekend day. Other studies of cyclists observed that the average distances for utilitarian trips are between $3.5 \mathrm{~km}$ and $7 \mathrm{~km}$ (Broach et al., 2011; Howard and Burns, 2001; Nankervis, 1999; Winters et al., 2010a; Winters et al., 2010b). These figures may be lower than what have been observed here as these studies do not include exercise trips or social and recreational trips. In terms of time spent cycling, the respondents cycle 42.6 min on a weekday and 31.9 min on a weekend day on average. Table 2 also shows that generally the cyclists travel at speeds of $10-20 \mathrm{~km} / \mathrm{hr}$. Although a great number of respondents describing themselves as highly skilled cyclists travel at higher speeds. In this survey, nearly $98 \%$ of the respondents describe themselves as being either competent or highly skilled cyclists. It has also been observed that, over $85 \%$ of the respondents are regular cyclists and cycle at least 3 days per week. The survey reveals that bicycles are used for social and recreational trips by the greatest number of respondents (65.4\%), and such trips consume on average $7.6 \%$ of their total time spent cycling. Bicycles are used for commuting trips by $58.2 \%$ of the respondents and on average such trips take $37.8 \%$ of their total cycling time. In 2006 , only $45 \%$ of these respondents cycled in Dublin; this figure grew each year to $90.9 \%$ in 2010 . Over $90 \%$ of the respondents, cycle from spring to autumn and $74.1 \%$ continue to cycle during the winter months. $93.7 \%$ of the respondents own a bicycle; it is thought that the remaining respondents make use of the bicycle sharing scheme available in the city. The survey also suggests high rates of safety accessory use; nearly $54 \%$ of the cyclists claim to wear a helmet and $88 \%$ use lights or reflective accessories while cycling at night. Similar studies from other countries, suggest lower rates of safety accessory use; $2.2 \%$ of the cyclists in Paris, 31.5\% in Boston (Osberg et al., 1998) and 44\% in Victoria (Robinson, 1996) wear helmets while cycling and $14.8 \%$ of the cyclists in Boston, $46.8 \%$ in Paris (Osberg et al., 1998), 40-60\% in Christchurch (Ferguson and Blampied, 1991) and 50\% in Edmonton (Hagel et al., 2007) use lights or reflective accessories while cycling at night. These differences may be due to the legal, cultural and social differences among the various cities and countries.

Initial analysis of the survey data looked at the travel behavior of the respondents while cycling in the city. In the survey questionnaire, the cyclists were presented with various alternative route choice scenarios and they were asked whether they would alter their routes under these scenarios. A qualitative Likert scale, with 5 options, was used to measure the likelihood of route alteration. $57.8 \%$ of the respondents stated that they would alter their routes to make use of continuous cycle lanes, while $50.4 \%$ and $50.6 \%$ of the respondents would alter their routes to use quiet roads and routes perceived as safe by the cyclists, respectively. There are a number of elements in a transportation network which are generally considered as hindrances to the cyclists and would often compel them to change 
their routes. The strongest aversion felt by the respondents was for roads with higher speed limits and for roads with poor quality surfaces, with $32.9 \%$ and $31.7 \%$ of the respondents respectively, stating they would alter their routes in order to avoid these roads. Only $10.9 \%$ of the respondent cyclists stated that they would alter their routes to avoid inconvenient right turn movements. Infrastructure to allow easier right turn movements for cyclists has recently been introduced to Dublin; however, such implementation may not improve the attractiveness of a route according to this survey. The respondents were also asked if they would consider changing to another mode of transportation under various weather conditions; $79.8 \%$ would change to an alternative mode under icy road conditions; $55.6 \%$ in heavy rain and $30.3 \%$ in temperatures below freezing. A study on students in the universities of Melbourne, Australia found that $40 \%$ of the respondent cyclists would change to another mode in rain and 66\% would do the same in icy and snowy conditions (Nankervis, 1999). In Dublin, more survey respondents are likely to change their mode of travel under adverse weather conditions as they may have better access to alternative modes, such as private cars, than a student-only population.

\section{Methods}

This section describes the survey method, its organization and distribution, as well as the methods used to analyze the survey data. In examining this data, it must be taken into consideration that the data collected from the survey is self-reported and may vary from the actual behavior of the respondent cyclists.

Principal Component Analysis (PCA) and Ordered Logistic Regression (OLR) are the chosen methods for analyzing the survey responses. PCA is a multivariate data analysis methodology similar to Factor Analysis (FA). Logistic regression is a powerful tool in establishing probabilities related typically to binary choices. However, there can be ordinal dependent variables for which an extension of the binary model, an ordered logistic regression model should be used. For detailed discussions on PCA and OLR, the reader is advised to refer to Hair (2010), Semmlow (2009), Hosmer and Lemeshow (2000), Jolliffe (2002) and Jambu (1991). Both of these methods have been widely used in the areas of cycling and other transportation studies (Ben-Elia and Ettema, 2011; Borgnat et al., 2011; Brown et al., 2009; Dupont et al., 2010; Heinen et al., 2011; Kiryu et al., 1997; Kiss et al., 2010; Ma et al., 2009; Morrongiello et al., 2010; Popuri et al., 2011; Winters et al., 2010a; Yannis et al., 2005; Yau, 2004).

Three models, namely the Safety Behavior Model, the Perceived Safety Model and the Cyclist-Network Interaction Model, were developed to analyze the survey responses using the above-mentioned methods. The Safety Behavior Model was developed to investigate the safety behavior of the cyclists in an urban multi-modal network of Dublin City. PCA was used to develop the model to analyze survey responses related to their attitudes and behaviors towards safety while cycling. The Perceived Safety Model was developed via OLR to investigate the determinants which influence a cyclist's perception of safety as compared to driving in the shared multi-modal transportation network of Dublin City. The final model, the Cyclist-Network Interaction Model was built via PCA to investigate the interaction between the cyclist and the elements of the shared multi-modal transportation network of Dublin City and to understand the perception of safety of the cyclists in relation to the existing 
infrastructures. The results from each of these models are discussed in the Analysis section of this article.

\section{Analysis}

The following subsections contain the findings of analysis according to each of the models conducted, namely the Safety Behavior Model, the Perceived Safety Model and the CyclistNetwork Interaction Model.

\subsection{Safety Behavior Model}

This model was developed to analyze the survey responses related to their attitude and behavior towards safety while cycling in a shared urban multimodal network of Dublin City. PCA was used to reveal the guiding factors. Initially, 31 variables were included in the analysis; of these, 5 were found to be insignificant (the use of a bicycle for travel to school/college, the use of a bicycle for organized racing, the distance and time cycled on an average weekday/weekend-day and average cyclist speed) and were therefore removed from the analysis. Performing PCA with the remaining variables, 8 eigenvectors were found to remain significant after having taken the latent root criterion into account.

Table 3 presents the results of the final analysis but it is noted that the model revealed a number of other results during analysis which are not displayed in this table; the respondent cyclists are significantly confident regarding their skills; people who wear safety accessories (helmets, high-visibility clothing, reflectors and lights) tend to claim that they are more compliant with the rules of the road; the majority of these cyclists tend to be commuters; and only the more experienced cyclists felt comfortable when cycling during night-time. Table 3 presents the significant eigenvalues, percentage of variance explained, factor loadings, means and standard errors of the variables grouped together according to factors which are related to each other. From this table, a number of interesting results can be inferred.

The likelihood of an accident due to pedestrians, rush-hour traffic, road surface quality, parked vehicles along road sides, buses and taxis in shared lanes are grouped together according to the similarity of the perceived risk that they present to the cyclists. This grouping indicates that if a cyclist feels the threat of an accident due to the presence of one of these factors, they will feel similarly about the other factors within this group. This result may be a cause of concern as these elements are encountered by cyclists on a regular basis within the transportation network. These above-mentioned factors move independently of the likelihood of an accident due to poor bicycle maintenance and lack of cycling skills. Table 3 shows that safety accessory use is not associated with the confidence of cyclists, regularity of cycling or the level of experience of cyclists, as the group containing variables related to safety accessory use moves independently from all other groups. The interim results of the PCA also revealed that the cyclists who use safety accessories are more compliant to the rules of the road. A lack of compliance with the rules of the road is associated with the cyclists who described themselves as being more experienced and confident and who tend to cycle more regularly within the network, as all these factors move together within a group. Another interesting point revealed by PCA is that the trip purposes are not related to any of the safety aspects and variables considered within the model. Finally, Table 3 indicates that the cyclists feel motorists to be both reckless and careless with regard to the presence of cyclists in Dublin's transportation network. This is a major 
cause for concern; as it is vital that all the modes cooperate with each other to ensure the safety of the shared space.

The overall ranked scores for the variables of the Safety Behavior Model are presented in Figure 1. The bar graph shows the degree of significance of the variables. The scores signify that the variables of similar signs are interpreted to be of similar influence in a binary sense. The policy implications of the findings of this model are discussed in further detail in the Discussion section.

\subsection{Perceived Safety Model}

The Perceived Safety Model was developed using the OLR technique to investigate the determinants which influence a cyclist's perception of safety as compared to driving in the shared multi-modal transportation network of Dublin City. Initially, 23 variables were included as explanatory variables in the Perceived Safety Model (Table 4). In Table 4, the coefficients, odds ratios, standard errors of the coefficients, indicative significance according to $p$-values and $95 \%$ confidence interval of the coefficients of the explanatory variables are presented. Age, regularity of cycling (number of days per week), use of urban roads, use of roads with no cycling facilities, use of bright colored/high-visibility clothing, compliance with the rules of the road and the attitude of vehicle drivers were identified as the significant determinants to influence the perception of safety of a cyclist when compared to driving.

The probabilities of describing cycling as safer than, as safe as, or less safe than driving, while the other explanatory variables were assumed constant, are displayed in Figures 2 and 3. Figure 2 indicates that, in all cases the respondent cyclists perceive cycling to be less safe than driving in Dublin, except with regard to compliance with the rules of the road. In this exceptional case, it is quite interesting to see that cyclists who claim to always follow the rules of the road are much more likely to describe cycling as safer than or as safe as driving in Dublin. The use of safety accessories do not have a large influence on the probability of describing cycling as less safe than driving. The cyclists who do not prefer to cycle on urban roads and on-road with no cycling facilities are nearly $80 \%$ likely to consider cycling to be less safe than driving. The cyclists who tend to prefer to do so are nearly $70 \%$ likely to consider cycling to be less safe than driving. This slight reduction in percentage of perceived risk may be related to the experience and the skills of the cyclists who are used to cycling in urban roads with higher traffic volume. The probability of describing cycling as safer than driving increases with the increased number of days cycled per week. This result may indicate that familiarity with the network, due to regular use, may decrease a cyclist's probability of describing cycling as less safe than driving within the network. Møller \& Hels (2008) also found that increased regularity decreased the perceived risk, for the specific case of the use of roundabouts. The results of the OLR model also indicate reckless and careless driver behavior is one of the major factors in cycling being perceived as less safe than driving.

Figure 3 presents the probability of cycling being perceived as a safe mode when compared with driving in Dublin according to the age of the cyclists. It is interesting to observe that the probability of describing cycling as safer than or as safe as driving grows with age. Consequently, older people are more likely to deem the cycling network as safer than the relatively younger population. This observation is a cause for concern, since it is the younger population who is and will constitute the largest proportion of beginner cyclists to contribute to the growing bicycle mode share in Dublin. Additionally, it is the younger population who 
will play a major role in influencing the growth and evolution of cycling as a preferred choice of travel mode. This warranted further analysis in this regard.

In addition to this model of all participants, further analysis was conducted to analyze and compare responses according to age (under 25 years of age, and 25 years of age or older) and gender. This analysis was also carried out using the OLR method. Table 5 shows the odds ratios of the variables of each of these models. The age specific model indicates that the factors that improve the perceived safety of cycling is quite different between the two age groups, except in two cases; first, the respondent cyclists of both age groups who tend to use safety accessories are more likely to describe cycling to be less safe than driving and second, the respondent cyclists of both age groups associated reckless attitude of drivers with a reduced perception of safety. Compliance with the rules of the road is another factor, where both age groups show similar choice behavior. Full compliance with the rules of the road among the older age group increases their perceived safety by 2.7 times compared to the older cyclists who do otherwise, while a general compliance with the rules among the younger cyclists increase their perceived safety by 4.2 times compared to others.

From the results in Table 5, it can be seen that the older cyclists experience an increased feeling of safety with a greater number of days cycled within a week. Among the younger age group, the more experienced cyclists are 1.8 times more likely to describe cycling as safe, than their less experienced colleagues. This is the only case where the experience of the respondents has been shown to be significant in influencing the perceived safety of the mode. The cyclists aged under 25, who prefer to cycle on urban roads tend to describe cycling in Dublin city to be safer than those who prefer to avoid this type of road. For the older cyclists who prefer to cycle on roads with no cycling facilities also tend to describe cycling in Dublin city to be safer than those who prefer otherwise.

The gender specific model shows that older female cyclists tend to perceive cycling to be safer than the younger ones. The regularity of cycling is significant to both male and female groups in increasing their perception of safety. The preference for cycling on urban roads for male cyclists and for cycling on shared bus-cycle lanes for female cyclists improve their tendency of describing cycling to be as safe as or safer than driving in Dublin city. A preference for using roads with no cycling facilities is also significant in improving the likelihood of describing cycling to be as safe as or safer than driving for both genders. Similar to age specific model, both male and female cyclists who tend to use safety accessories are more likely to describe cycling to be less safe than driving. The policy implications of the findings of this model are discussed in further detail in the discussions section.

\subsection{Cyclist-Network Interaction Model}

The interaction between the cyclists and the elements of the shared multi-modal transportation network of Dublin was investigated through PCA to understand the perception of safety of the cyclists in relation to the existing infrastructures. Initially, the Cyclist-Network Interaction Model included 28 variables, of which 3 were found to be insignificant (the use of off-road paths and trails, light rain and strong winds) and therefore were removed as they are not related to the interaction of a cyclist with the elements of the transportation network.

Table 6 presents the significant eigenvalues, the percentage of variance explained, factor loadings, and means and standard errors of the variables of the Cyclist-Network Interaction Model. Respondents were asked if they would alter their routes to avoid or make use of 
various factors encountered within the network that are often described as hindrances or beneficial to cyclists. The results reveal that the likelihood of cyclists altering their routes to make use of routes perceived as safe, quiet roads, well-lit streets, continuous cycle lanes and amenities are grouped together. This means that the cyclists who tend to (or not to) alter their routes for one of these factors will do similarly for all other factors within the group. Interestingly, all factors studied, and viewed as beneficial to the cyclists are contained within this group, explaining the largest amount of variance within the data modeled. This indicates that the presence of one or more of these factors improves the attractiveness of a route. Factors considered as hindrances move in 2 separate groups; the first of these groups includes stop signs and traffic lights, while the second includes steep gradients, roads with high speed limits, traffic congestion, right turns, parked cars along road-side and roundabouts. This implies that those cyclists who will change their route to avoid stops signs and traffic lights will not necessarily do the same for the second group of factors considered as hindrances. It is interesting to note that right turns are not included in the first group along with stop signs and traffic lights.

In terms of road types studied, urban, residential and suburban roads are grouped together (off-road paths and trails were found to be insignificant in this analysis). In terms of bicycle infrastructure, the cyclists preferring to use kerb-side cycle lanes also prefer to use shared bus-cycle lanes, while those who prefer roads without cycling facilities prefer not to cycle on footpaths. These cyclists will also alter their routes to avoid roads with poor quality surfaces. The final point displayed by this model shows that with increased regularity of cycling, the tendency to change to alternative modes in adverse weather conditions decreases.

Figure 4 represents the ranked scores for the variables of the Cyclist-Network Interaction Model. The figure shows the degree of significance of each variable within the model and the scores signify that the variables of similar signs are interpreted to be of similar influence in a binary sense.

\section{Discussion}

Analysis of the survey responses of the cyclists in Dublin City has revealed several new areas, in which improvement could increase the perceived safety of cyclists. The effects of such improvements and their policy implications are discussed in details in the next subsection. Then, the limitations that should be considered while developing or implementing policies based on the findings of this study are mentioned.

\subsection{Policy Implications}

The analysis has shown that the use of safety accessories (helmets, high visibility/bright colored clothing and lights/reflective accessories) is not associated with an improvement in perception of safety among cyclists' compared to driving in Dublin, but instead is shown to be associated with a decreased safety experience. The presence of situations perceived by cyclists as potentially unsafe has led the cyclists to make use of such safety accessories, but has not helped them to overcome their fear of such situations. Therefore, making their use mandatory among cyclists may be of little or no benefit to the improvement of the perceived safety of cyclists which is required to promote cycling as a viable mode of transportation in Dublin. Such a measure may even prove counteractive to improve cycle mode share, as has been presented by a before-and-after study of the mandatory helmet use for Australian 
cyclists (Robinson, 1996). Following the findings of the analysis in this paper, it can be expected that mandatory use of other safety accessories may result in similar outcomes.

To promote cycling as a major mode of transportation it is important to improve the perceived safety of the mode to be at least comparable to the level of other existing major modes of travel, such as driving. This research highlights the importance of considering policy variables, such as the cyclists' compliance with the rules of the road, in the study of cyclist safety perceptions. Analysis has shown that $74 \%$ of the cyclists, who claim to be fully compliant with the rules of the road, are likely to consider cycling as safer than or at least as safe as driving in Dublin, yet the survey has revealed that $87.5 \%$ of the participants admit to breaking the rules of the road. Road safety initiatives encouraging improved compliance among cyclists can therefore be beneficial in improving the perceived safety of cycling. Increased compliance with the rules of the road can also be achieved through enforcement as is done for cars in the form of fines and 'points' on offenders. However, such enforcement may decrease the attraction of the mode to a certain population of cyclists and hence a debate is necessary to reach consensus. It is important to note, regular, confident and experienced cyclists have reported to be less compliant with the rules of the road.

To maximize safety, urban road networks are designed for motor-vehicle drivers to accommodate variable competence levels among users and some non-compliance with the rules of the road. Establishing cycling as a major mode of travel would also require such design considerations for bicycle infrastructures to be in place. The analysis shows that regular, confident and experienced cyclists prefer to cycle on-road and not on segregated facilities. Hence, policies and network design should consider that on-road cyclists may infringe the rules of the road, and design for these cases bearing in mind that cyclists are categorized as vulnerable road users.

Similar to Parkin et al. (2007), it was found that the provision of infrastructures does not necessarily correspond to an increased attractiveness of a route. Segregated facilities provide a more comfortable environment for beginner/learner cyclists, but for more conversant cyclists, improvement of driver attitudes may prove more beneficial to their perceived safety as they often prefer to cycle on-road. This study is the first of its kind to analyze the effect of driver attitudes on the perceived safety of cyclists. Careless and reckless driver behavior have has been shown by analysis to have a major detrimental effect on the safety experience of cyclists. Campaigns to encourage cyclist-driver cooperation within the network may help combat Dublin's 'road rage' problems.

The respondent cyclists also believed that there are potential accident risks due to lack of cycling skills and poor bicycle maintenance skills. Cycling workshops and community initiatives, for young, new and improving cyclists may prove beneficial for providing education and information about the rules of the road, bicycle care and safe cyclist practices for cycling in a multi-modal shared space. With this increased knowledge, cyclists can feel more confident and conversant within the transportation network.

The analysis demonstrates that the cyclists prefer less busy and quiet roads, roads with street lights, routes perceived as safe and routes with continuous cycling facilities. Cycling policy, based on user feedback, should emphasize on improving safety along routes which have been identified by cyclists as unsafe. Provision of street lights, signs for alternative routes to busy roads and continuous cycling facilities on priority routes should be considered to attract more non-cyclists into cycling. The provision of more information through websites 
and social networks on alternative routes within the road network which are viewed as safer and more comfortable by cyclists may be advantageous to cyclists.

Young cyclists were identified as more likely to perceive cycling to be less safe than driving, than older cyclists. The economic boom in the nineties saw a drastic drop in bicycle mode share throughout Ireland and therefore the younger generations have not been exposed to the culture of cycling; feeling less comfortable and less safe than older generations when using a bicycle in a multi-modal network. To make cycling an intrinsic part of Irish mobility, it may be beneficial to introduce the knowledge and culture in school. Introducing cycling education at the primary school level could encourage cycling among a younger population, would inform them on the safe and responsible use of the shared multi-modal transportation network and would also educate the future drivers to appreciate the safety requirements of cyclists within the network.

Analysis has revealed the perceived safety of cycling increases with regularity of use and with an increasing number of days cycled per week, the probability of considering cycling as less safe than driving in Dublin falls. Therefore, it is suggested that transportation policies which encourage regular cycling activities such as the 'Bike to Work' scheme should be expanded and further encouraged. The 'Bike to Work' scheme promotes regular commuting activity by bicycle through tax-break incentive. This scheme is currently available in Ireland solely to employees of companies registered to the scheme. Further provision of incentives which encourage regular bicycle use for additional activities would broaden the scope of the scheme to other areas of bicycle use, and hence to a larger population of cyclists and potential cyclists.

The respondent cyclists (79\%) envisage that the presence of pedestrians and cycle lanes on footpaths are likely causes of an accident. This result confirms the findings of previous studies investigating the relative safety of various types of cycling infrastructure that shared use (pedestrian-cycle) paths are one of the least safe options for cyclists (Aultman-Hall and Hall, 1998a; Aultman-Hall and Kaltenecker, 1999; Lam and Huang, 1992; Moore et al., 2011; Moritz, 1997; Si et al., 2011). This could suggest that the introduction of new cycle lanes on footpaths and busy shopping districts may not be beneficial. Poor road condition was identified by $81 \%$ of the respondents as another major factor negatively influencing the perception of safety, which is similar to the findings of studies elsewhere (Doherty et al., 2000). It is therefore recommended that the National Roads Authority and town/city councils should focus on maintaining the kerb-side surfaces on the on-road cycle lanes and roads with no cycling facilities.

Overall, current cyclists feel that cycling is less safe than driving in Dublin city. Hence, it is important to implement the recommended policy changes towards the safety of cycling and to inform cyclists of such changes. Policy considerations directly related to the safety of cyclists can establish the viability of cycling as a safe mode of travel.

\subsection{Limitations}

The following three limitations should be considered while developing or implementing policies based on the findings of this study. First, the study was based on a fixed-response questionnaire survey and has associated limitations. The majority of the respondents were young and male cyclists. Although this over-representation was also evident in the anonymous journey-to-work travel survey dataset available for the entire population of 
Dublin City (Central Statistics Office, 2006), there remains a possibility of residual bias in our study.

Second, the study was based on responses of existing cyclists; majority of whom were selfreported experienced cyclists. This may not correspond to their actual skill levels. Consequently, their perception of safety and their safety behavior may be influenced by their perceived skill levels.

Third, the study has assessed perceived safety through self-reports as opposed to utilizing data on actual collisions and injuries. Cycling incidents are severely underreported and consequently it is difficult to study the relationship between perceived and actual safety for a large population of existing cyclists in a city. For successful policy implementation, the actual incident reports of both minor and major accidents should be investigated and taken into account.

\section{Conclusion}

This paper presents a comprehensive study on cyclists' perception of safety while using a shared multi-modal urban transportation network. A questionnaire based survey of 1954 existing cyclists was carried out in Dublin to obtain an overall view of how the network, its users and their attitudes impact on the perceptions of safety of cyclists. The study considered a wide range of variables from all parts of the network, such as cyclists' compliance with the rules of the road, attitudes of bus/taxi/car drivers, weather conditions, presence of accident blackspots on the route, etc. These variables are expected to be important in influencing the perception of safety among cyclists but were never studied in the past. The analysis showed many of these variables are critical in improving the perceived safety of cyclists and possible policy changes to make such improvement were suggested in the paper. The main inferences from the study are the following:

- $\quad$ Cycling is truly perceived as an unsafe mode of travel compared to driving even by the existing cyclists who consider themselves to be competent users of the mode. Hence, it is important to identify the determinants of perceived safety among cyclists and to recommend policy changes accordingly to improve such perception.

- In understanding the safety experience of cyclists the behavioral dynamics of shared space is often overlooked and this study addresses that by considering the attitude of bus/taxi/car drivers, presence of local amenities, presence of accident blackspots, etc. Among other factors, negative driver attitude has been identified as a key factor which affects the perception of safety of cyclists.

- $\quad$ Cycling is not envisaged as a major mode of travel either by cyclists or by planners or other users of the transportation network. As a result, enforcement and infrastructure design for the comfort and non-compliance of cyclists are not considered in multi-modal urban transportation networks. However, such considerations may prove beneficial.

- $\quad$ The analysis also identified variables which are often considered as essential for perceived safety of cyclists but are not that critical in reality and the policy changes related to these variables which might affect the attractiveness of the mode were discussed. 
The policy recommendations based on the findings of the analysis, if implemented, should positively influence how cycling is perceived among both cyclists and non-cyclists in terms of safety and in turn may establish cycling as a viable major mode of travel. 


\section{References}

Aultman-Hall, L., Hall, F.L. (1998a) Ottawa-Carleton commuter cyclist on-and off-road incident rates. Accident Analysis \& Prevention 30, 29-43.

Aultman-Hall, L., Hall, F.L. (1998b) Research design insights from a survey of urban bicycle commuters. Transportation Research Record 1636, 21-28.

Aultman-Hall, L., Kaltenecker, M.G. (1999) Toronto bicycle commuter safety rates. Accident Analysis \& Prevention 31, 675-686.

Ben-Elia, E., Ettema, D. (2011) Changing commuters' behavior using rewards: A study of rush-hour avoidance. Transportation Research Part F: Traffic Psychology and Behaviour 14, 354-368.

Bíl, M., Bílová, M., Müller, I. (2010) Critical factors in fatal collisions of adult cyclists with automobiles. Accident Analysis \& Prevention 42, 1632-1636.

Borgnat, P., Abry, P., Flandrin, P., Robardet, C., Rouquier, J.-B., Fleury, E., (2011) Shared Bicycles in a City: A Signal Processing and Data Analysis Perspective. Advances in Complex Systems 14, 415-438.

Broach, J., Gliebe, J., Dill, J. (2011) Bicycle route choice model deveolped using revealed preference GPS data. 90th Annual Meeting of the Transportation Research Board.

Brown, T., O'Connor, J., Barkatsas, A. (2009) Instrumentation and motivations for organised cycling: the development of the Cyclist Motivation Instrument (CMI). Journal of Sports Science and Medicine 8, 211-218.

Cameron, M.H., Vulcan, A.P., Finch, C.F., Newstead, S.V. (1994) Mandatory bicycle helmet use following a decade of helmet promotion in Victoria, Australia - An evaluation. Accident Analysis \& Prevention 26, 325-337.

Central Statistics Office (2006) Census of Population of Ireland 2006. Place of Work, Census of Anonymised Records (POWCAR) Users Guide. Central Statistics Office, Dublin.

de Lapparent, M. (2005) Individual cyclists' probability distributions of severe/fatal crashes in large french urban areas. Accident Analysis \& Prevention 37, 1086-1092.

Department of Transport (2009) National Cycle Policy Framework. Department of Transport, Dublin, Ireland.

Depreitere, B., Van Lierde, C., Maene, S., Plets, C., Vander Sloten, J., Van Audekercke, R., Van der Perre, G., Goffin, J. (2004) Bicycle-related head injury: a study of 86 cases. Accident Analysis \& Prevention 36, 561-567.

Dill, J. (2009) Bicycling for transportation and health: The role of infrastructure. Journal of Public Health Policy 30, S95-S110. 
Doherty, S.T., Aultman-Hall, L., Swaynos, J. (2000) Commuter cyclist accident patterns in Toronto and Ottawa. Journal of Transportation Engineering 126, 21-26.

Dublin Chamber of Commerce (2005) Transport 21, Future for Dublin. Dublin Chamber of Commerce, Dublin.

Dupont, E., Martensen, H., Papadimitriou, E., Yannis, G. (2010) Risk and protection factors in fatal accidents. Accident Analysis \& Prevention 42, 645-653.

Ekman, R., Schelp, L., Welander, G., Svanström, L. (1997) Can a combination of local, regional and national information substantially increase bicycle-helmet wearing and reduce injuries? Experiences from sweden. Accident Analysis \& Prevention 29, 321-328.

Ferguson, B., Blampied, N.M. (1991) Unenlightened: An unsuccessful attempt to promote the use of cycle lights at night. Accident Analysis \& Prevention 23, 561-571.

Forester, J. (1993) Effective Cycling, Sixth ed., MIT Press, Massachusetts, USA.

Hagel, B.E., Lamy, A., Rizkallah, J.W., Belton, K.L., Jhangri, G.S., Cherry, N., Rowe, B.H. (2007) The prevalence and reliability of visibility aid and other risk factor data for uninjured cyclists and pedestrians in Edmonton, Alberta, Canada. Accident Analysis \& Prevention 39, 284-289.

Hair, J.F., Black, W.C., Babin, B.J., Anderson, R.E. (2010) Multivariate Data Analysis. A Global Perspective., Seventh ed., Pearson Prentice Hall, Upper Saddle River, New Jersey.

Heinen, E., Maat, K., Wee, B.V. (2011) The role of attitudes toward characteristics of bicycle commuting on the choice to cycle to work over various distances. Transportation Research Part D: Transport and Environment 16, 102-109.

Hopkinson, P., Wardman, M. (1996) Evaluating the demand for new cycle facilities. Transport Policy 3, 241-249.

Hosmer, D.W., Lemeshow, S. (2000) Applied Logistic Regression, Second ed., John Wiley and Sons, New York, USA.

Howard, C., Burns, E. (2001) Cycling to work in Phoenix: route choice, travel behavior, and commuter characteristics. Transporation Research Record 1773, 39-46.

Hughes, R.G., Harkey, D.L. (1997) Cyclists' perception of risk in a virtual environment: effects of lane conditions, traffic speed, and traffic volume. Proceedings of the 1997 Conference on Traffic Congestion and Traffic Safety in the 21st Century, June 8, 1997 June 11, 1997, Chicago, IL, USA, 132-138.

Hughes, R.G., Harkey, D.L. (1999) Using Visual Simulation to Evaluate Bicyclists' Perceptions of Selected Risk Factors. University of North Carolina Highway Safety Research Center, Chapel Hill, North Carolina.

Jambu, M. (1991) Exploratory and Multivariate Data Analysis. Academic Press Inc., Boston 
Jolliffe, I.T. (2002) Principal Component Analysis, Second ed., Springer, New York.

Keegan, O., Galbraith, J. (2005) Attitudes of Cyclists and Car Commuters to Cycling in Dublin. Paper presented at Velocity Conference, Dublin.

Kim, J.K., Kim, S., Ulfarsson, G.F., Porrello, L.A. (2007) Bicyclist injury severities in bicyclemotor vehicle accidents. Accident Analysis \& Prevention 39, 238-251.

Kiryu, T., Takahashi, K., Ogawa, K. (1997) Multivariate analysis of muscular fatigue during bicycle ergometer exercise. Biomedical Engineering, IEEE Transactions on 44, 665-672.

Kiss, K., Pótó, Z., Pintér, A., Sárközy, S. (2010) Bicycle injuries in children: An analysis based on demographic density. Accident Analysis \& Prevention 42, 1566-1569.

Klobucar, M.S., Fricker, J.D. (2007) Network evaluation tool to improve real and perceived bicycle safety. Transportation Research Record 2031, 25-33.

Lam, W.H.K., Huang, H.-J. (1992) A combined trip distribution and assignment model for multiple user classes. Transportation Research Part B: Methodological 26, 275-287.

Landis, B., Vattikuti, V., Brannick, M. (1997) Real-time human perceptions: toward a bicycle level of service. Transportation Research Record 1578, 119-126.

Landis, B.W. (1996) The Bicycle System Performance Measures: The Interaction Hazard and Latent Demand Score Models. ITE Journal 66, 18-26.

Landis, B.W., Vattikuti, V.R., Ottenberg, R.M., Petritsch, T.A., Guttenplan, M., Crider, L.B. (2003) Intersection Level of Service for the Bicycle Through Movement. Transportation Research Record 1828, 101-106.

Leden, L., Garder, P., Pulkkinen, U. (2000) Expert judgment model applied to estimating the safety effect of a bicycle facility. Accident Analysis and Prevention 32, 589-599.

Ma, Z., Chunfu, S., Hao, Y., Sheqiang, M. (2009) Analysis of the logistic model for accident severity on urban road environment. Intelligent Vehicles Symposium, 2009 IEEE, 983-987.

Maimaris, C., Summer, C.L., Browning, C., Palmer, C.R. (1994) Injury patterns in cyclists attending an accident and emergency department: a comparison of helmet wearers and non-wearers. BMJ 308, 1537-1540.

McIntosh, A., Dowdell, B., Svensson, N. (1998) Pedal cycle helmet effectiveness: A field study of pedal cycle accidents. Accident Analysis \& Prevention 30, 161-168.

McMorrow, K., Ghosh, B. (2011) Analysis of Non-Motorized Commuter Journeys in Irish Cities. Proceedings of the 90th Annual Meeting of Transportation Research Board.

Ministerie van Verkeer en Waterstaat (2009) Cycling in the Netherlands. Ministerie van Verkeer en Waterstaat, Fietsberaad. 
Møller, M., Hels, T. (2008) Cyclists' perception of risk in roundabouts. Accident Analysis and Prevention 40, 1055-1062.

Moore, J.K., Kooijman, J.D.G., Schwab, A.L. (2011) Rider motion identification during normal bicycling by means of principal component analysis. Multibody System Dynamics, 25, 225-244.

Moritz, W.E. (1997) Survey of North American Bicycle Commuters. Transportation Research Record 1578, 91-101.

Morrongiello, B.A., Cusimano, M., Barton, B.K., Orr, E., Chipman, M., Tyberg, J., Kulkarini, A., Khanlou, N., Masi, R., Bekele, T. (2010) Development of the BACKIE questionnaire: A measure of children's behaviors, attitudes, cognitions, knowledge, and injury experiences. Accident Analysis \& Prevention 42, 75-83.

Nankervis, M. (1999) The effect of weather and climate on bicycle commuting. Transportation Research Part A: Policy and Practice 33, 417-431.

Noland, R.B., Kunreuther, H. (1995) Short-run and long-run policies for increasing bicycle transportation for daily commuter trips. Transport Policy 2, 67-79.

Osberg, J.S., Stiles, S.C., Asare, O.K. (1998) Bicycle safety behavior in Paris and Boston. Accident Analysis \& Prevention 30, 679-687.

Parkin, J., Meyers, C. (2010) The effect of cycle lanes on the proximity between motor traffic and cycle traffic. Accident Analysis \& Prevention 42, 159-165.

Parkin, J., Wardman, M., Page, M. (2007) Models of perceived cycling risk and route acceptability. Accident Analysis \& Prevention 39, 364-371.

Popuri, Y., Proussaloglou, K., Ayvalik, C., Koppelman, F., Lee, A. (2011) Importance of traveler attitudes in the choice of public transportation to work: findings from the Regional Transportation Authority Attitudinal Survey. Transportation 38, 643-661.

Povey, L.J., Frith, W.J., Graham, P.G. (1999) Cycle helmet effectiveness in New Zealand. Accident Analysis \& Prevention 31, 763-770.

Pucher, J. (2001) Cycling safety on bikeways vs. roads. Transportation Quarterly 55, 11-99.

Pucher, J., Dill, J., Handy, S. (2010) Infrastructure, programs, and policies to increase bicycling: An international review. Preventive Medicine 50, S106-S125.

Road Safety Authority (2010) Pedal Cyclists Road Casualties 1998 - 2008. RSA, Mayo.

Robinson, D.L. (1996) Head injuries and bicycle helmet laws. Accident Analysis \& Prevention 28, 463-475.

Robinson, D.L. (2001) Changes in head injury with the New Zealand bicycle helmet law. Accident Analysis \& Prevention 33, 687-691. 
Scuffham, P., Alsop, J., Cryer, C., Langley, J.D. (2000) Head injuries to bicyclists and the New Zealand bicycle helmet law. Accident Analysis \& Prevention 32, 565-573.

Scuffham, P.A., Langley, J.D. (1997) Trends in cycle injury in new zealand under voluntary helmet use. Accident Analysis \& Prevention 29, 1-9.

Semmlow, J.M. (2009) Biosignal and medical image processing, Second ed., Rutgers University, Piscataway, New Jersey, USA.

Si, B., Zhang, H., Zhong, M., Yang, X. (2011) Multi-criterion system optimization model for urban multimodal traffic network. Science China Technological Sciences 54, 947-954.

Stutts, J.C., Hunter, W.W. (1998) Police reporting of pedestrians and bicyclists treated in hospital emergency rooms. Transportation Research Record 1635, 88-92.

Tilahun, N.Y., Levinson, D.M., Krizek, K.J. (2007) Trails, lanes, or traffic: Valuing bicycle facilities with an adaptive stated preference survey. Transportation Research Part A: Policy and Practice 41, 287-301.

Turner, S.A., Roozenburg, A.P., Francis, T. (2006) Predicting accident rates for cyclists and pedestrians. Land Transport New Zealand Research Report 289.

Waldman, J.A. (1977) Cycling in Towns. A Quantitative Investigation. LTR1 Working paper 3, Department of Transport, London.

Wardman, M., Tight, M., Page, M. (2007) Factors influencing the propensity to cycle to work. Transportation Research Part A: Policy and Practice 41, 339-350.

Wegman, F., Zhang, F., Dijkstra, A. (2012) How to make more cycling good for road safety? Accident Analysis \& Prevention 44, 19-29.

Welander, G., Ekman, R., Svanström, L., Schelp, L., Karlsson, A. (1999) Bicycle injuries in Western Sweden: a comparison between counties. Accident Analysis \& Prevention 31, 1319.

Winters, M., Davidson, G., Kao, D., Teschke, K. (2010a) Motivators and deterrents of bicycling: comparing influences on decisions to ride. Transportation 38, 153-168.

Winters, M., Teschke, K., Grant, M., Brauer, M. (2010b) How far out of the way will we travel? Built environment influences on route selection for bicycle and car travel. Transportation Research Record 2190, 1-10.

Yannis, G., Kanellopoulou, A., Aggeloussi, K., Tsamboulas, D. (2005) Modelling driver choices towards accident risk reduction. Safety Science 43, 173-186.

Yau, K.K.W. (2004) Risk factors affecting the severity of single vehicle traffic accidents in Hong Kong. Accident Analysis \& Prevention 36, 333-340.

Zegeer, C. (1994) FHWA Study Tour for Pedestrian and Bicyclist Safety in England, Germany, and The Netherlands. US Department of Transportation, Washington, DC. 


\section{List of Figures}

Figure 1 Scores for the variables of the Safety Behavior Model

Figure 2 Probability of the occurrence of an event under various factors considered by the Perceived Safety Model

Figure 3 Probability of describing cycling as being safer, about as safe or less safe than driving according to the age of cyclists for the Perceived Safety Model

Figure 4 Scores for the variables of the Cycling Network Interaction Model

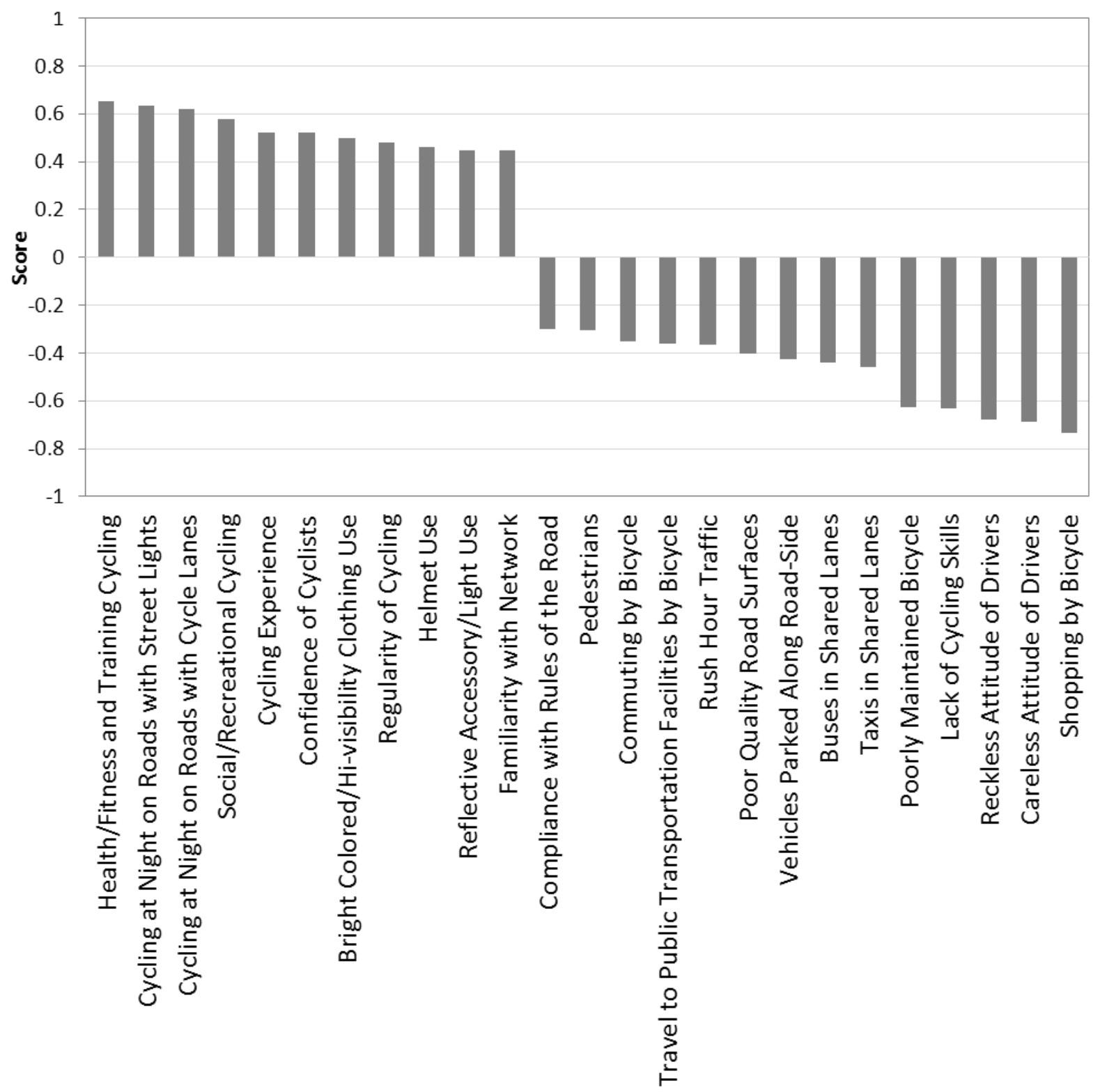

Figure 1 Scores for the variables of the Safety Behavior Model 


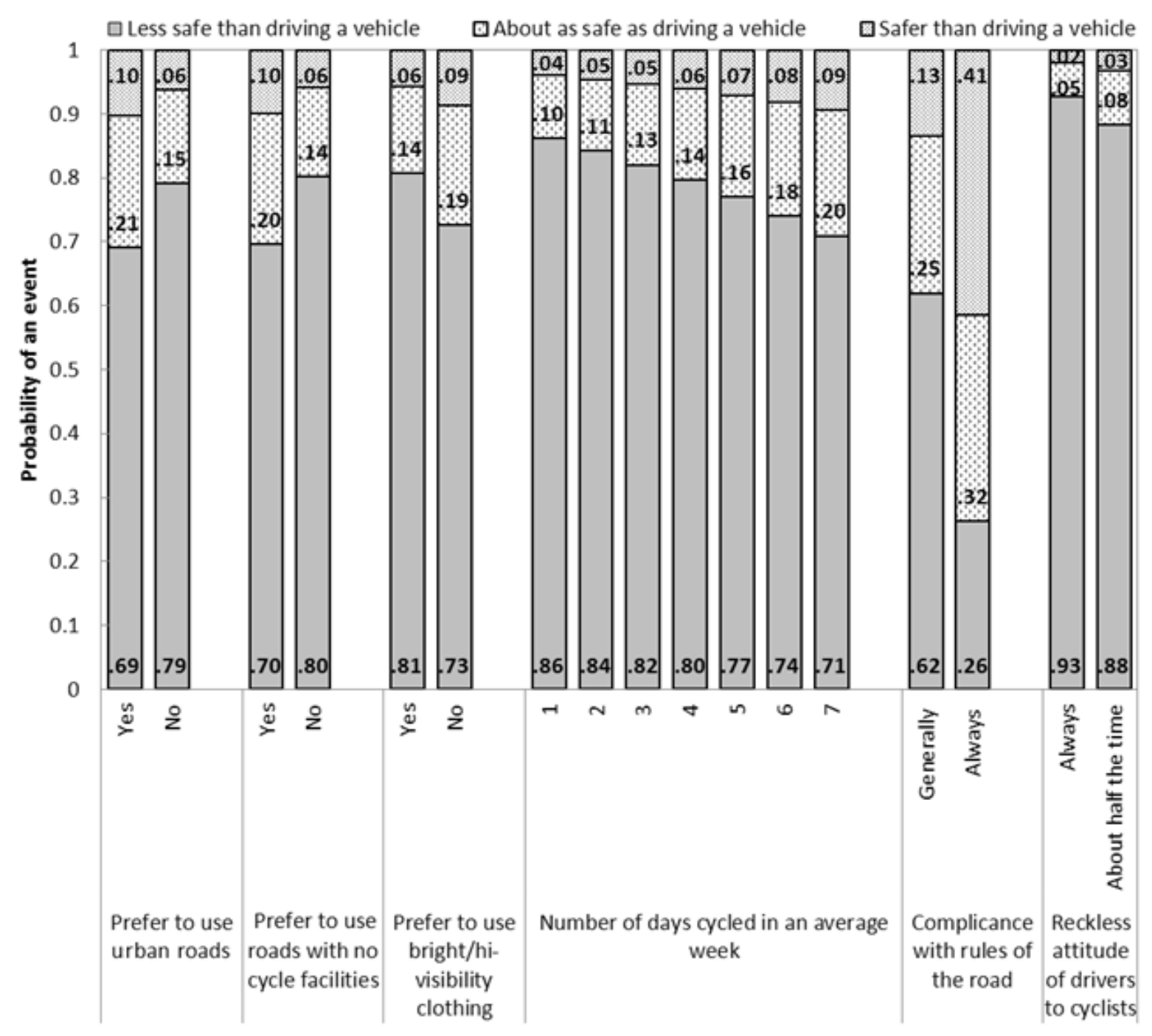

Figure 2 Probability of the occurrence of an event under various factors considered by the Perceived Safety Model 


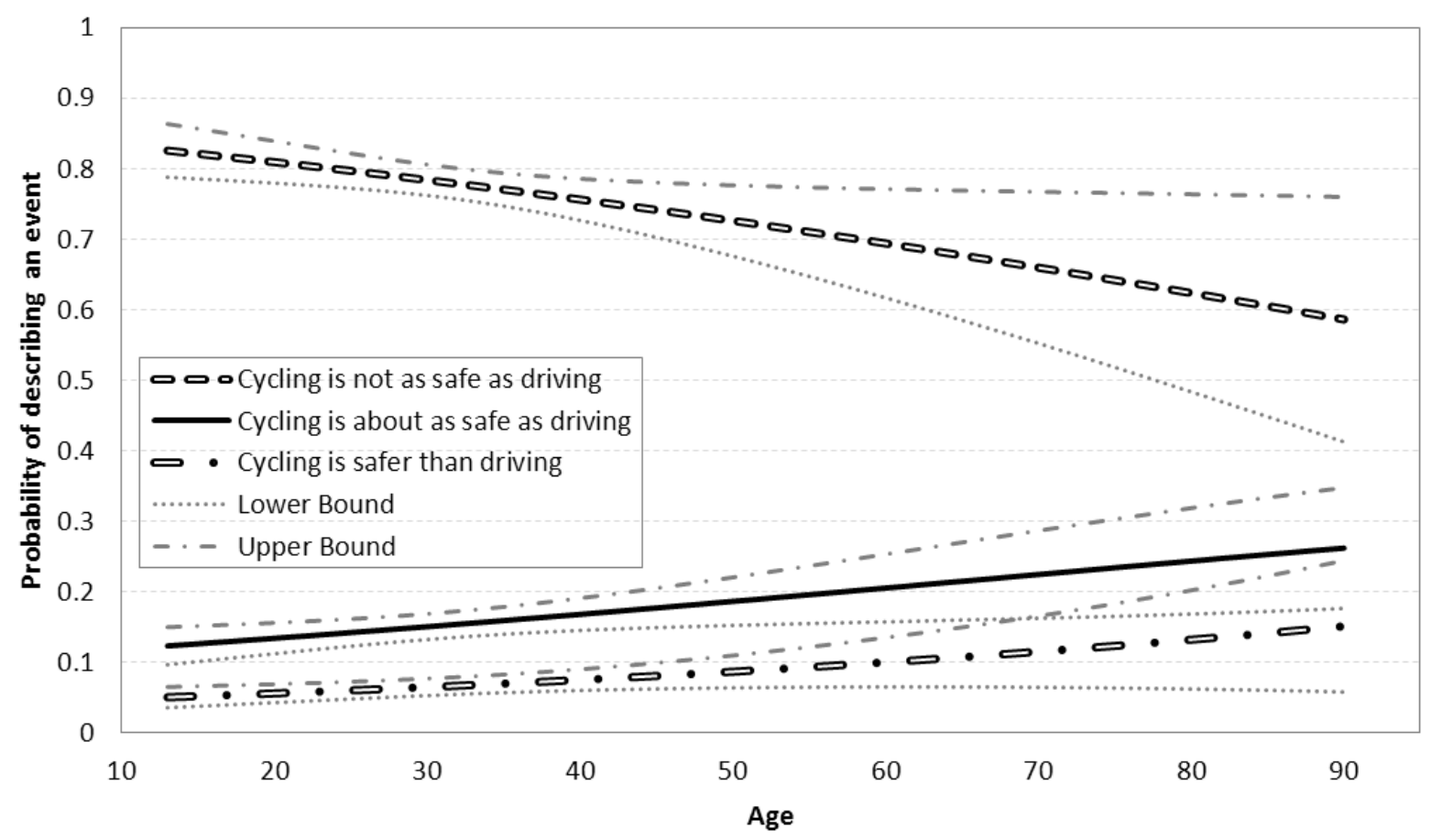

Figure 3 Probability of describing cycling as being safer, about as safe or less safe than driving according to the age of cyclists for the Perceived Safety Model 


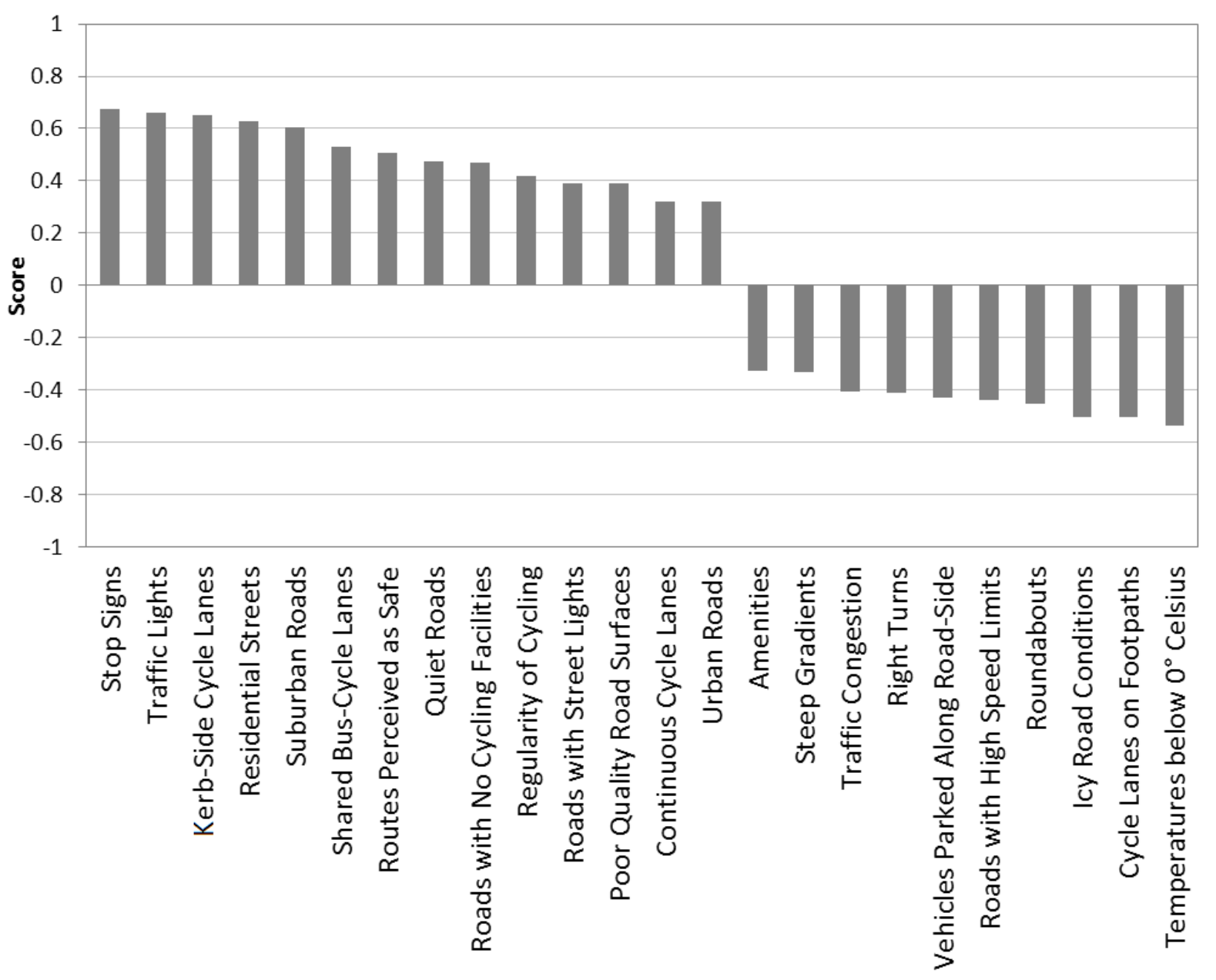

Figure 4 Scores for the variables of the Cycling Network Interaction Model 


\section{List of Tables}

Table 1 Cyclist safety/risk perception literature and variables collected by each study

Table 2 Survey data description

Table 3 Eigenvalues, percentage variance explained, factor loadings, means and standard errors of the variables of the Safety Behavior Model

Table 4 Coefficients, odds ratios, the standard errors \& the $95 \%$ confidence interval of these coefficients of the Perceived Safety Model

Table 5 Odds ratios of the variables of the Perceived Safety Models, categorized by age and gender

Table 6 Eigenvalues, percentage variance explained, factor loadings, means and standard errors of the variables of the Cyclist-Network Interaction Model 
Table 1 Cyclist safety/risk perception literature and variables collected by each study

\begin{tabular}{|c|c|c|c|c|c|c|c|c|c|c|c|c|}
\hline \multirow[b]{2}{*}{ Author, Year } & \multirow[b]{2}{*}{ Location } & \multirow[b]{2}{*}{ Who was asked? } & \multirow[b]{2}{*}{ Perception of } & \multirow[b]{2}{*}{ Method } & \multicolumn{8}{|c|}{ Cyclist Specific } \\
\hline & & & & & 总 & $\begin{array}{l}\bar{d} \\
\overline{0} \\
\overline{0} \\
0 \\
\end{array}$ & 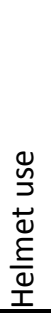 & 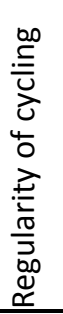 & 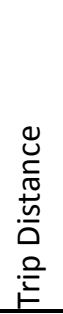 & 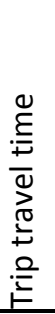 & 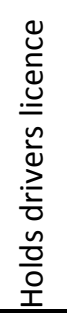 & 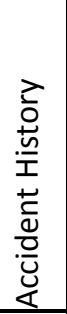 \\
\hline Moller \& Hels, 2008 & Roundabout & Cyclists & Risk \& danger & $\begin{array}{l}\text { Interview at } \\
\text { roundabout } \\
\text { site }\end{array}$ & $*$ & $*$ & $*$ & $*$ & $*$ & & $*$ & $*$ \\
\hline Parkin et al., 2007 & $\begin{array}{l}\text { Link \& intersection } \\
\text { (route as a whole) }\end{array}$ & $\begin{array}{l}\text { cyclists and non- } \\
\text { cyclists }\end{array}$ & Risk & Video clips & & & & & & & & \\
\hline Klobucar \& Fricker, 2007 & Link & Cyclists & $\begin{array}{l}\text { Safety \& } \\
\text { discomfort }\end{array}$ & Video clips & & & & & & & & \\
\hline Landis et al., 2003 & Intersection & Cyclists & Safety & Test course & & & & & & & & \\
\hline Leden et al., 2000 & Bicycle crossing & Cycling experts & Risk & Survey & & & & & & & & \\
\hline Hughes \& Harkey, 1999 & Link, curb-side lane & Cyclists & Risk & $\begin{array}{l}\text { Video } \\
\text { simulations }\end{array}$ & & & & & & & & \\
\hline Harkey et al., 1998 & Link & Cyclists & Comfort & Video clips & & & & & & & & \\
\hline Hughes \& Harkey, 1997 & Link, curb-side lane & Cyclists & Risk & $\begin{array}{l}\text { video } \\
\text { simulations }\end{array}$ & & & & & & & & \\
\hline Landis et al., 1997 & Link & Cyclists & $\begin{array}{l}\text { Hazards } \\
\text { (stress/comfort) }\end{array}$ & Test course & & & & & & & & \\
\hline Landis, 1996 & Link & Cyclists & Hazards & & & & & & & & & \\
\hline Noland, 1995 & & $\begin{array}{l}\text { Walkers, cyclists, } \\
\text { transit users \& } \\
\text { vehicle drivers }\end{array}$ & Risk & Survey & $*$ & $*$ & & & & * & & \\
\hline $\begin{array}{l}\text { Landis, } 1994 \\
\text { Sorton and Walsh, } 1994\end{array}$ & $\begin{array}{l}\text { Link } \\
\text { Link }\end{array}$ & $\begin{array}{l}\text { Cyclists } \\
\text { Cyclists }\end{array}$ & $\begin{array}{l}\text { Hazards } \\
\text { stress }\end{array}$ & $\begin{array}{l}\text { Survey } \\
\text { Video clips }\end{array}$ & & & & & & & & \\
\hline
\end{tabular}


Table 1 cont. Cyclist safety/risk perception literature and variables collected by each study

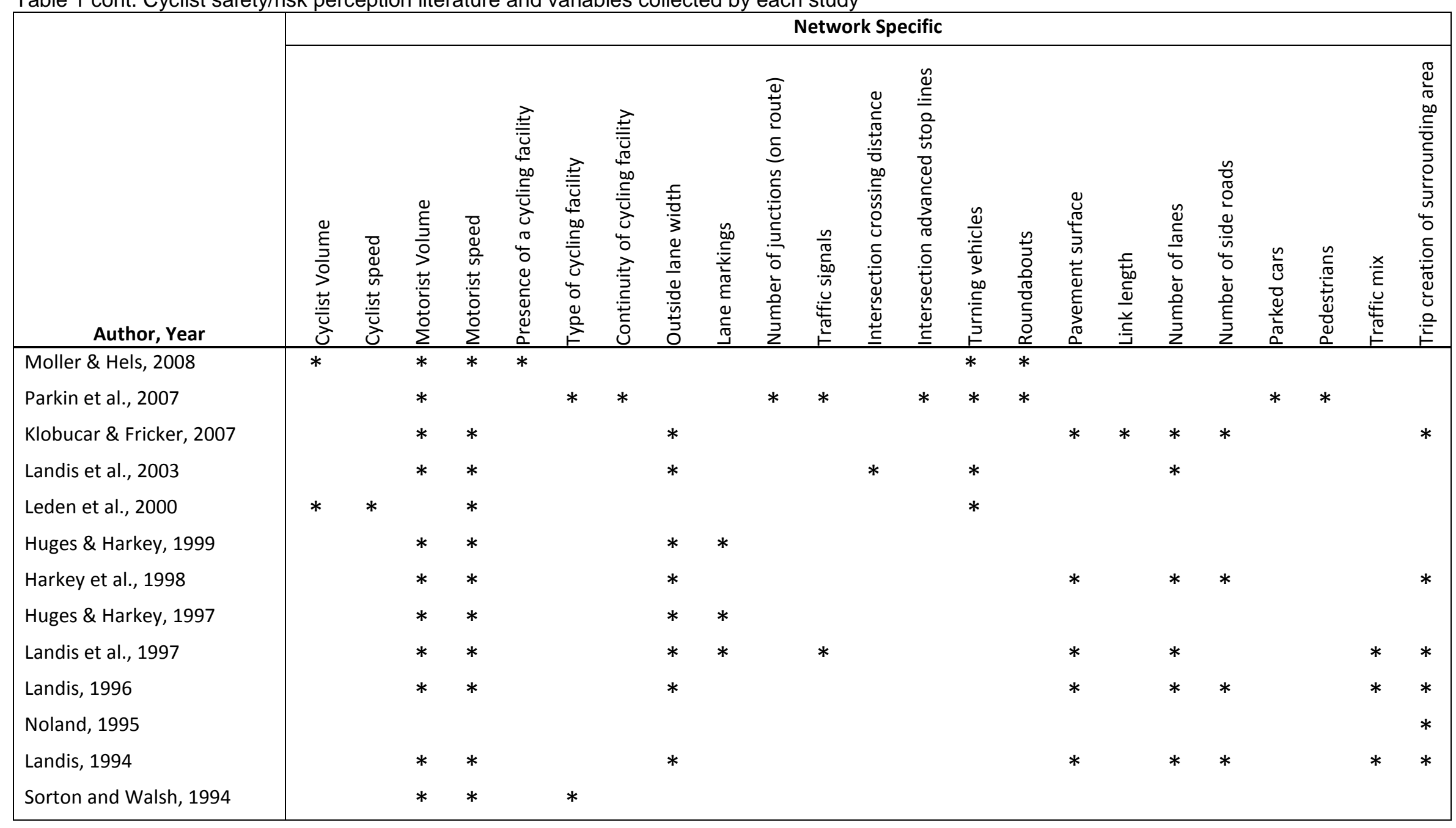


Table 2 Survey data description

\begin{tabular}{|c|c|c|c|c|c|c|}
\hline \multirow{2}{*}{$\begin{array}{l}\text { Socio-Demographic } \\
\text { Characteristics }\end{array}$} & \multicolumn{2}{|c|}{ Inexperienced } & \multicolumn{2}{|c|}{ Competent } & \multicolumn{2}{|c|}{ Highly Skilled } \\
\hline & 36 & $2.08 \%$ & 871 & $50.29 \%$ & 825 & $47.63 \%$ \\
\hline \multicolumn{7}{|l|}{ Gender } \\
\hline Male & 4 & $0.23 \%$ & 445 & $25.69 \%$ & 654 & $37.76 \%$ \\
\hline Female & 32 & $1.85 \%$ & 418 & $24.13 \%$ & 167 & $9.64 \%$ \\
\hline \multicolumn{7}{|l|}{ Age } \\
\hline Less than 25 years old & 19 & $1.10 \%$ & 283 & $16.34 \%$ & 255 & $14.72 \%$ \\
\hline 25 to 44 years old & 11 & $0.64 \%$ & 400 & $23.09 \%$ & 423 & $24.42 \%$ \\
\hline 45 to 64 years old & 0 & $0.00 \%$ & 98 & $5.66 \%$ & 90 & $5.20 \%$ \\
\hline More than 64 years old & 0 & $0.00 \%$ & 7 & $0.40 \%$ & 4 & $0.23 \%$ \\
\hline \multicolumn{7}{|l|}{ Employment Status } \\
\hline Full time & 7 & $0.40 \%$ & 360 & $20.79 \%$ & 399 & $23.04 \%$ \\
\hline Part-time & 0 & $0.00 \%$ & 31 & $1.79 \%$ & 29 & $1.67 \%$ \\
\hline Student & 26 & $1.50 \%$ & 419 & $24.19 \%$ & 350 & $20.21 \%$ \\
\hline Unemployed & 0 & $0.00 \%$ & 12 & $0.69 \%$ & 7 & $0.40 \%$ \\
\hline Other & 3 & $0.17 \%$ & 49 & $2.83 \%$ & 40 & $2.31 \%$ \\
\hline \multicolumn{7}{|l|}{ Household Structure } \\
\hline Single person - shared accommodation & 14 & $0.81 \%$ & 327 & $18.88 \%$ & 276 & $15.94 \%$ \\
\hline $\begin{array}{l}\text { Single person - unshared } \\
\text { accommodation }\end{array}$ & 1 & $0.06 \%$ & 62 & $3.58 \%$ & 65 & $3.75 \%$ \\
\hline Lone parent with resident child(ren) & 3 & $0.17 \%$ & 21 & $1.21 \%$ & 22 & $1.27 \%$ \\
\hline Couple with resident child(ren) & 4 & $0.23 \%$ & 195 & $11.26 \%$ & 216 & $12.47 \%$ \\
\hline Couple with no resident children & 7 & $0.40 \%$ & 147 & $8.49 \%$ & 138 & $7.97 \%$ \\
\hline Other & 7 & $0.40 \%$ & 119 & $6.87 \%$ & 108 & $6.24 \%$ \\
\hline
\end{tabular}


Table 2 cont. Survey data description

\begin{tabular}{|c|c|c|c|c|c|c|}
\hline \multirow{2}{*}{ Cyclists' Trip Characteristics } & \multicolumn{2}{|c|}{ Inexperienced } & \multicolumn{2}{|c|}{ Competent } & \multicolumn{2}{|c|}{ Highly Skilled } \\
\hline & 36 & $2.08 \%$ & 871 & $50.29 \%$ & 825 & $47.63 \%$ \\
\hline \multicolumn{7}{|l|}{ Regularity of Cycling (days/week) } \\
\hline 1 to 2 days every week & 14 & $0.81 \%$ & 170 & $9.82 \%$ & 56 & $3.23 \%$ \\
\hline 3 to 5 days every week & 20 & $1.15 \%$ & 519 & $29.97 \%$ & 419 & $24.19 \%$ \\
\hline 6 to 7 days every week & 2 & $0.12 \%$ & 182 & $10.51 \%$ & 350 & $20.21 \%$ \\
\hline \multicolumn{7}{|l|}{$\begin{array}{l}\text { Time Spent on Cycling on an } \\
\text { Average Weekday }\end{array}$} \\
\hline Less than $30 \mathrm{~min}$ & 17 & $0.98 \%$ & 325 & $18.76 \%$ & 209 & $12.07 \%$ \\
\hline $30 \mathrm{~min}$ to 1 hour & 17 & $0.98 \%$ & 418 & $24.13 \%$ & 415 & $23.96 \%$ \\
\hline More than 1 hour & 2 & $0.12 \%$ & 128 & $7.39 \%$ & 201 & $11.61 \%$ \\
\hline \multicolumn{7}{|l|}{$\begin{array}{l}\text { Time Spent on Cycling on an } \\
\text { Average Weekend Day }\end{array}$} \\
\hline Less than 30min & 30 & $1.73 \%$ & 585 & $33.78 \%$ & 429 & $24.77 \%$ \\
\hline $30 \mathrm{~min}$ to 1 hour & 6 & $0.35 \%$ & 145 & $8.37 \%$ & 155 & $8.95 \%$ \\
\hline More than 1 hour & 0 & $0.00 \%$ & 141 & $8.14 \%$ & 241 & $13.91 \%$ \\
\hline \multicolumn{7}{|l|}{$\begin{array}{l}\text { Distance Cycled on an Average } \\
\text { Weekday }\end{array}$} \\
\hline Less than $5 \mathrm{~km}$ & 26 & $1.50 \%$ & 372 & $21.48 \%$ & 225 & $12.99 \%$ \\
\hline 5.1 to $10 \mathrm{~km}$ & 6 & $0.35 \%$ & 224 & $12.93 \%$ & 209 & $12.07 \%$ \\
\hline 10.1 to $15 \mathrm{~km}$ & 2 & $0.12 \%$ & 124 & $7.16 \%$ & 137 & $7.91 \%$ \\
\hline More than $15 \mathrm{~km}$ & 2 & $0.12 \%$ & 151 & $8.72 \%$ & 254 & $14.67 \%$ \\
\hline \multicolumn{7}{|l|}{$\begin{array}{l}\text { Distance Cycled on an Average } \\
\text { Weekend Day }\end{array}$} \\
\hline Less than $5 \mathrm{~km}$ & 32 & $1.85 \%$ & 619 & $35.74 \%$ & 425 & $24.54 \%$ \\
\hline 5.1 to $10 \mathrm{~km}$ & 2 & $0.12 \%$ & 74 & $4.27 \%$ & 102 & $5.89 \%$ \\
\hline 10.1 to $15 \mathrm{~km}$ & 1 & $0.06 \%$ & 50 & $2.89 \%$ & 47 & $2.71 \%$ \\
\hline More than $15 \mathrm{~km}$ & 1 & $0.06 \%$ & 128 & $7.39 \%$ & 251 & $14.49 \%$ \\
\hline \multicolumn{7}{|l|}{ Average Travel Speed } \\
\hline Less than $10 \mathrm{~km} / \mathrm{hr}$ & 5 & $0.29 \%$ & 45 & $2.60 \%$ & 11 & $0.64 \%$ \\
\hline 10 to $20 \mathrm{~km} / \mathrm{hr}$ & 15 & $0.87 \%$ & 409 & $23.61 \%$ & 317 & $18.30 \%$ \\
\hline More than $20 \mathrm{~km} / \mathrm{hr}$ & 0 & $0.00 \%$ & 148 & $8.55 \%$ & 334 & $19.28 \%$ \\
\hline Don't know & 16 & $0.92 \%$ & 269 & $15.53 \%$ & 163 & $9.41 \%$ \\
\hline \multicolumn{7}{|l|}{ Trip Purpose } \\
\hline Commute to/from work & 16 & $0.92 \%$ & 502 & $28.98 \%$ & 545 & $31.47 \%$ \\
\hline Commute to/from school or college & 24 & $1.39 \%$ & 458 & $26.44 \%$ & 408 & $23.56 \%$ \\
\hline Travel to other forms of public transport & 7 & $0.40 \%$ & 130 & $7.51 \%$ & 134 & $7.74 \%$ \\
\hline Shopping & 19 & $1.10 \%$ & 443 & $25.58 \%$ & 423 & $24.42 \%$ \\
\hline Social/recreation & 24 & $1.39 \%$ & 561 & $32.39 \%$ & 557 & $32.16 \%$ \\
\hline Health/fitness training & 13 & $0.75 \%$ & 412 & $23.79 \%$ & 460 & $26.56 \%$ \\
\hline Organized racing & 1 & $0.06 \%$ & 37 & $2.14 \%$ & 130 & $7.51 \%$ \\
\hline \multicolumn{7}{|l|}{$\begin{array}{l}\text { Driver's Attitude (Perceived by the } \\
\text { Cyclists) }\end{array}$} \\
\hline Always reckless & 3 & $0.92 \%$ & 25 & $28.98 \%$ & 40 & $31.47 \%$ \\
\hline Usually reckless & 6 & $1.39 \%$ & 151 & $26.44 \%$ & 134 & $23.56 \%$ \\
\hline Reckless about half the time & 12 & $0.40 \%$ & 260 & $7.51 \%$ & 238 & $7.74 \%$ \\
\hline Seldom reckless & 12 & $1.10 \%$ & 417 & $25.58 \%$ & 395 & $24.42 \%$ \\
\hline Never reckless & 3 & $1.39 \%$ & 18 & $32.39 \%$ & 18 & $32.16 \%$ \\
\hline
\end{tabular}


Table 3 Eigenvalues, percentage variance explained, factor loadings, means and standard errors of the variables of the Safety Behavior Model

\begin{tabular}{|c|c|c|c|c|c|}
\hline $\begin{array}{l}\text { Eigen- } \\
\text { value }\end{array}$ & $\begin{array}{l}\text { \% variance } \\
\text { explained }\end{array}$ & Loading & Variable & Mean & $\begin{array}{l}\text { Std. } \\
\text { Error }\end{array}$ \\
\hline \multirow{6}{*}{3.06} & \multirow{6}{*}{12.22} & -0.304 & $\begin{array}{l}\text { Likelihood of an accident due to } \\
\text { pedestrians }\end{array}$ & $2.335^{b}$ & 0.024 \\
\hline & & -0.366 & $\begin{array}{l}\text { Likelihood of an accident due to rush } \\
\text { hour traffic }\end{array}$ & $1.924^{\mathrm{b}}$ & 0.021 \\
\hline & & -0.403 & $\begin{array}{l}\text { Likelihood of an accident due to poor } \\
\text { quality road surfaces }\end{array}$ & $2.386^{\mathrm{b}}$ & 0.024 \\
\hline & & -0.425 & $\begin{array}{l}\text { Likelihood of an accident due to vehicles } \\
\text { parked along road-side }\end{array}$ & $2.574^{\mathrm{b}}$ & 0.023 \\
\hline & & -0.439 & $\begin{array}{l}\text { Likelihood of an accident involving a bus } \\
\text { in a shared cycle lane }\end{array}$ & $2.237^{\mathrm{b}}$ & 0.024 \\
\hline & & -0.459 & $\begin{array}{l}\text { Likelihood of an accident involving a taxi } \\
\text { in a shared cycle lane }\end{array}$ & $2.611^{\mathrm{b}}$ & 0.025 \\
\hline \multirow{3}{*}{2.28} & \multirow{3}{*}{9.10} & 0.499 & Bright colored/hi-visibility clothing use & $3.641^{\mathrm{C}}$ & 0.037 \\
\hline & & 0.460 & Helmet use & $3.234^{c}$ & 0.044 \\
\hline & & 0.449 & Reflective accessory and/or light use & $4.463^{\mathrm{C}}$ & 0.025 \\
\hline \multirow{4}{*}{1.78} & \multirow{4}{*}{7.12} & 0.521 & Experience of cyclists & $2.478^{\mathrm{a}}$ & 0.013 \\
\hline & & 0.520 & Confidence of cyclists & $3.052^{c}$ & 0.025 \\
\hline & & 0.478 & Regularity of cycling & $4.636^{\mathrm{d}}$ & 0.041 \\
\hline & & -0.301 & Compliance with rules of the road & $2.539^{c}$ & 0.020 \\
\hline \multirow{3}{*}{1.65} & \multirow{3}{*}{6.61} & 0.636 & $\begin{array}{l}\text { Use of roads with street lights while } \\
\text { cycling at night }\end{array}$ & $1.194^{\mathrm{a}}$ & 0.018 \\
\hline & & 0.621 & Use of cycle lanes while cycling at night & $1.378^{\mathrm{a}}$ & 0.022 \\
\hline & & 0.445 & Familiarity with cycling in Dublin & $3.231^{\mathrm{c}}$ & 0.039 \\
\hline \multirow{3}{*}{1.57} & \multirow{3}{*}{6.29} & 0.652 & Cycling for health/fitness and training & $17.904^{\mathrm{e}}$ & 0.658 \\
\hline & & 0.580 & Cycling for social/recreational purposes & $15.283^{\mathrm{e}}$ & 0.515 \\
\hline & & -0.350 & Cycling for commuting purposes & $37.846^{\mathrm{e}}$ & 0.912 \\
\hline \multirow[b]{2}{*}{1.23} & \multirow[b]{2}{*}{4.92} & -0.677 & Reckless attitude of drivers & $3.279^{\mathrm{C}}$ & 0.023 \\
\hline & & -0.688 & Careless attitude of drivers & $2.615^{\mathrm{c}}$ & 0.022 \\
\hline \multirow{2}{*}{1.18} & \multirow{2}{*}{4.70} & -0.363 & Cycling to public transportation facilities & $3.124^{\mathrm{e}}$ & 0.273 \\
\hline & & -0.736 & Cycling for shopping purposes & $7.558^{\mathrm{e}}$ & 0.294 \\
\hline \multirow{2}{*}{1.02} & \multirow{2}{*}{4.09} & -0.625 & $\begin{array}{l}\text { Likelihood of an accident due to a poorly } \\
\text { maintained bicycle }\end{array}$ & $3.379^{b}$ & 0.022 \\
\hline & & -0.631 & $\begin{array}{l}\text { Likelihood of an accident due to lack of } \\
\text { cycling skills }\end{array}$ & $3.695^{b}$ & 0.016 \\
\hline
\end{tabular}


Table 4 Coefficients, odds ratios, the standard errors \& the 95\% confidence interval of these coefficients of the Perceived Safety Model

\begin{tabular}{|c|c|c|c|c|c|}
\hline \multirow{2}{*}{$\begin{array}{l}\text { Is cycling safer than driving in Dublin? } \\
\text { Gender }\end{array}$} & \multirow{2}{*}{$\begin{array}{r}\text { Coeff. } \\
0.794\end{array}$} & \multirow{2}{*}{$\begin{array}{l}\text { Odds } \\
\text { Ratio } \\
0.825\end{array}$} & \multirow{2}{*}{$\begin{array}{l}\text { Std. } \\
\text { Err. } \\
0.118\end{array}$} & \multicolumn{2}{|c|}{$\begin{array}{l}\text { [95\% Conf. } \\
\text { Interval] }\end{array}$} \\
\hline & & & & 0.133 & 1.456 \\
\hline Age & 0.042 & $1.016^{*}$ & 0.006 & -0.247 & 0.331 \\
\hline Regularity of bicycle use & -0.053 & $1.170^{\star \star}$ & 0.049 & -0.773 & 0.666 \\
\hline Cyclist's experience & 0.147 & 1.159 & 0.156 & -0.117 & 0.412 \\
\hline Balanced cyclists & -0.445 & 1.043 & 0.154 & -0.732 & -0.158 \\
\hline Confident cyclists & -0.461 & 0.948 & 0.348 & -0.806 & -0.116 \\
\hline Distance traveled & 0.157 & 1.001 & 0.002 & 0.074 & 0.240 \\
\hline Use of urban roads & 0.001 & $1.700^{\star \star}$ & 0.315 & -0.003 & 0.005 \\
\hline Use of suburban roads & 0.530 & 1.055 & 0.165 & 0.167 & 0.894 \\
\hline Use of residential streets & 0.053 & 1.167 & 0.176 & -0.254 & 0.360 \\
\hline Use of park/scenic trials & 0.154 & 1.031 & 0.170 & -0.142 & 0.451 \\
\hline Use of cycle lanes on footpath & 0.030 & 0.863 & 0.121 & -0.293 & 0.353 \\
\hline Use of off-road scenic cycle paths & -0.147 & 1.033 & 0.176 & -0.423 & 0.128 \\
\hline Use of kerb-side cycle lanes & 0.033 & 0.837 & 0.112 & -0.302 & 0.367 \\
\hline Use of shared bus-cycle lanes & -0.178 & 1.173 & 0.185 & -0.440 & 0.085 \\
\hline Use of roads with no cycling facilities & 0.160 & $1.765^{\star \star}$ & 0.276 & -0.149 & 0.468 \\
\hline Use of helmets & 0.568 & 0.790 & 0.113 & 0.262 & 0.875 \\
\hline Use of bright colored/hi-visibility clothing & -0.236 & $0.637^{\star *}$ & 0.090 & -0.516 & 0.044 \\
\hline Use of reflective accessories/lights & -0.451 & 0.861 & 0.171 & -0.729 & -0.173 \\
\hline Full compliance with rules of the road & -0.150 & $1.928^{\star}$ & 0.543 & -0.538 & 0.238 \\
\hline General compliance with rules of the road & 0.657 & $2.213^{*}$ & 0.747 & 0.105 & 1.209 \\
\hline Attitude of drivers towards cyclists is usually reckless & -0.193 & $0.641^{\star *}$ & 0.094 & -0.474 & 0.088 \\
\hline Attitude of drivers towards cyclists is always reckless & 0.016 & $0.631^{\star \star}$ & 0.111 & 0.004 & 0.028 \\
\hline
\end{tabular}

** represents a $p$ value of $0.01,{ }^{*}$ represents a $p$ value of 0.05 
Table 5 Odds ratios of the variables of the Perceived Safety Models, categorized by age and gender

\begin{tabular}{|l|ll|ll|}
\hline Is cycling safer than driving in Dublin? & $\begin{array}{c}\text { Under } \\
\mathbf{2 5}\end{array}$ & $\begin{array}{c}\mathbf{2 5} \text { and } \\
\text { over }\end{array}$ & Male & Female \\
\hline Gender & 0.818 & $1.483^{\star}$ & - & - \\
Age & - & - & 1.009 & $1.024^{\star}$ \\
Regularity of bicycle use & 1.152 & $1.167^{\star \star}$ & $1.161^{\star \star}$ & $1.149^{\star}$ \\
Cyclist's experience & $1.792^{\star}$ & 0.951 & 1.207 & 1.025 \\
Balanced cyclists & 0.757 & 0.982 & 0.969 & 1.175 \\
Confident cyclists & 0.735 & 1.347 & 0.769 & 3.786 \\
Distance traveled & 1.000 & 1.002 & 1.001 & 1.003 \\
Use of urban roads & $1.804^{\star}$ & 1.465 & $1.989^{\star \star}$ & 0.779 \\
Use of suburban roads & 0.895 & 1.146 & 1.146 & 0.813 \\
Use of residential streets & 1.219 & 1.235 & 1.322 & 1.104 \\
Use of park/scenic trials & 0.961 & 0.985 & 0.942 & 1.149 \\
Use of cycle lanes on footpath & 0.942 & 0.911 & 0.896 & 0.740 \\
Use of off-road scenic cycle paths & 0.930 & 1.065 & 0.963 & 1.181 \\
Use of kerb-side cycle lanes & 0.851 & 0.789 & 0.889 & 0.689 \\
Use of shared bus-cycle lanes & 0.879 & 1.367 & 0.983 & $1.890^{\star}$ \\
Use of roads with no cycle facilities & 1.333 & $1.908^{\star \star}$ & $1.604^{\star \star}$ & $2.444^{\star \star}$ \\
Use of helmets & 1.013 & $0.707^{\star}$ & 0.906 & $0.591^{*}$ \\
Use of bright colored/hi-visibility clothing & $0.539^{\star}$ & $0.664^{\star}$ & $0.644^{\star}$ & 0.753 \\
Use of reflective accessories/lights & 1.149 & 0.618 & 1.047 & $0.496^{\star}$ \\
Full compliance with rules of the road & 1.617 & $2.709^{\star}$ & 1.756 & 3.118 \\
General compliance with rules of the road & $4.204^{\star}$ & 2.408 & 1.742 & 4.517 \\
Attitude of drivers towards cyclists is usually reckless & $0.483^{\star}$ & $0.645^{\star}$ & $0.633^{\star}$ & $0.558^{\star}$ \\
Attitude of drivers towards cyclists is always reckless & 0.979 & $0.466^{\star *}$ & 0.735 & $0.507^{*}$ \\
\hline
\end{tabular}

** represents a $p$ value of $0.01,{ }^{*}$ represents a $p$ value of 0.05 
Table 6 Eigenvalues, percentage variance explained, factor loadings, means and standard errors of the variables of the Cyclist-Network Interaction Model

\begin{tabular}{|c|c|c|c|c|c|}
\hline $\begin{array}{l}\text { Eigen- } \\
\text { value }\end{array}$ & $\begin{array}{l}\text { \% variance } \\
\text { explained }\end{array}$ & Loading & Variable & Mean & $\begin{array}{l}\text { Std. } \\
\text { Error }\end{array}$ \\
\hline \multirow{5}{*}{3.44} & \multirow{5}{*}{13.76} & 0.531 & $\begin{array}{l}\text { Alter route to use routes perceived as } \\
\text { safe }\end{array}$ & $3.936^{b}$ & 0.032 \\
\hline & & 0.507 & Alter route to use quite roads & $3.956^{\mathrm{b}}$ & 0.032 \\
\hline & & 0.416 & Alter route to use roads with street lights & $3.864^{\mathrm{b}}$ & 0.032 \\
\hline & & 0.390 & Alter route to use continuous cycle lanes & $4.005^{\mathrm{b}}$ & 0.033 \\
\hline & & 0.320 & $\begin{array}{l}\text { Alter route to use amenities (e.g. Shops } \\
\text { and cafes) }\end{array}$ & $2.509^{b}$ & 0.040 \\
\hline \multirow[b]{2}{*}{2.19} & \multirow[b]{2}{*}{8.74} & 0.675 & Alter route to avoid stop signs & $2.171^{b}$ & 0.034 \\
\hline & & 0.662 & Alter route to avoid traffic lights & $2.498^{\mathrm{b}}$ & 0.036 \\
\hline \multirow{3}{*}{1.92} & \multirow{3}{*}{7.69} & 0.630 & Use of residential streets & $1.763^{\mathrm{a}}$ & 0.022 \\
\hline & & 0.620 & Use of suburban roads & $1.726^{\mathrm{a}}$ & 0.021 \\
\hline & & 0.320 & Use of urban roads & $1.278^{\mathrm{a}}$ & 0.016 \\
\hline \multirow{4}{*}{1.61} & \multirow{4}{*}{6.43} & 0.471 & Regularity of cycling & $4.636^{\mathrm{C}}$ & 0.041 \\
\hline & & -0.453 & Icy road conditions & $4.115^{\mathrm{b}}$ & 0.027 \\
\hline & & -0.504 & Heavy rain conditions & $3.236^{\mathrm{b}}$ & 0.035 \\
\hline & & -0.539 & Temperatures below $0^{\circ}$ & $2.605^{\mathrm{b}}$ & 0.032 \\
\hline \multirow{3}{*}{1.40} & \multirow{3}{*}{5.60} & 0.474 & Use of roads with no cycling facilities & $1.469^{\mathrm{a}}$ & 0.020 \\
\hline & & 0.391 & Alter route to avoid poor quality road & $3.469^{b}$ & 0.033 \\
\hline & & -0.503 & Use of cycle lanes on the footpath & $2.122^{\mathrm{a}}$ & 0.021 \\
\hline \multirow{6}{*}{1.24} & \multirow{6}{*}{4.94} & -0.325 & Alter route to avoid steep gradients & $1.823^{b}$ & 0.038 \\
\hline & & -0.334 & $\begin{array}{l}\text { Alter route to avoid roads with high speed } \\
\text { limits }\end{array}$ & $2.161^{b}$ & 0.039 \\
\hline & & -0.408 & Alter route to avoid traffic congestion & $1.898^{\mathrm{b}}$ & 0.038 \\
\hline & & -0.409 & Alter route to avoid right turns & $1.498^{\mathrm{b}}$ & 0.036 \\
\hline & & -0.431 & $\begin{array}{l}\text { Alter route to avoid parked cars along } \\
\text { road-side }\end{array}$ & $1.885^{\mathrm{b}}$ & 0.032 \\
\hline & & -0.441 & Alter route to avoid roundabouts & $1.681^{\mathrm{b}}$ & 0.037 \\
\hline \multirow[b]{2}{*}{1.11} & \multirow[b]{2}{*}{4.45} & 0.649 & Use of curb-side cycle lanes & $1.998^{\mathrm{a}}$ & 0.023 \\
\hline & & 0.603 & Use of shared bus-cycle lanes & $1.481^{\mathrm{a}}$ & 0.020 \\
\hline
\end{tabular}

${ }^{a}$ range of values: $1-3^{b}$ range of values: $1-5^{c}$ range of values: $1-7$ 